\title{
Métodos de tortura del terrorismo de Estado en Uruguay y valoración médico-legal de su idoneidad para causar lesiones graves o gravísimas
}

\author{
Hugo Rodríguez Almada*, Frances Borches Duhalde ${ }^{\dagger}$ Natalia Bazán ${ }^{\ddagger}$, \\ Sylvia Gamero§, Fernanda Lozano§, Rafael Roó
}

\section{Resumen}

La Medicina Legal tiene entre sus misiones el diagnóstico de la tortura como forma de contribución a las investigaciones judiciales y a la reparación de las víctimas. En Uruguay se desarrollan numerosos procedimientos administrativos y criminales referidos al período del terrorismo de Estado (entre el 27 de junio de 1973 y el 28 de febrero de 1985). Si bien el delito de tortura es un delito de lesa humanidad imprescriptible, se tipificó en la Ley № 18.026 de 26 de setiembre de 2006. La jurisprudencia nacional ha desestimado su tipificación en los casos del período del terrorismo de Estado en base al principio de no irretroactividad de la ley penal. Paralelamente, la Fiscalía Especializada en Crímenes de Lesa Humanidad ha requerido numerosos informes respecto de la posibilidad de que los métodos de tortura aplicados por el terrorismo de Estado en Uruguay pudieran causar lesiones graves o gravísimas. Objetivo general: contribuir al conocimiento de los crímenes del terrorismo de Estado en Uruguay, aportando así a la realización de los estándares internacionales de verdad, justicia, memoria y reparación.

Objetivos específicos: 1. Describir los métodos de tortura empleados. 2. Determinar su idoneidad para producir lesiones graves o gravísimas.

Metodología: el estudio se basó en las investigaciones históricas nacionales sobre el terrorismo de Estado, así como en la jurisprudencia en la materia, la revisión de la bibliografía internacional, la fisiopatología de situaciones análogas y los actuales consensos nacionales sobre los supuestos fácticos incluidos en los tipos penales de lesiones graves y gravísimas.

Resultados: en el período del terrorismo de Estado en Uruguay ha sido característica la aplicación de torturas a gran escala y en forma sistemática. Los métodos más habitualmennte aplicados fueron el encapuchamiento, la privación de agua, alimentos y reposo, la exposición al frío, las golpizas, incluido el teléfono, el plantón, el colgamiento, el caballete, el submarino húmedo y seco, la picana eléctrica y las agresiones sexuales. Los distintos métodos de tortura física incluyen un sufrimiento

\footnotetext{
* Profesor Director del Departamento de Medicina Legal y Ciencias Forenses. Facultad de Medicina. Universidad de la República. Uruguay. † Asistente del Departamento de Medicina Legal y Ciencias Forenses. Facultad de Medicina. Universidad de la República. Uruguay. † Profesora Adjunta (cont.) del Departamento de Medicina Legal y Ciencias Forenses. Facultad de Medicina. Universidad de la República. Uruguay.

$\S$ Profesora Adjunta del Departamento de Medicina Legal y Ciencias Forenses. Facultad de Medicina. Universidad de la República. Uruguay. II Profesor Adjunto del Departamento de Medicina Legal y Ciencias Forenses. Facultad de Medicina. Universidad de la República. Uruguay. Departamento de Medicina Legal y Ciencias Forenses. Facultad de Medicina. Universidad de la República.

Correspondencia: Dr. Hugo Rodríguez. Correo electrónico: hrodriguez@fmed.edu.uy

Los autores declaran no tener conflictos de intereses.

Recibido: 30/9/18

Aprobado: 21/11/18
} 
psíquico. A través de mecanismos específicos, todos resultan idóneos para ocasionar daños que encuadran en diversos supuestos de los delitos de lesiones graves y gravísimas. En las mujeres embarazadas, todos estos métodos de tortura son eficaces para interrumpir el aborto 0 adelantar el parto.

Conclusiones: existió un patrón en los métodos de tortura sistemática empleados por el terrorismo de Estado que incluyó métodos omisivos, posicionales, traumáticos, eléctricos, asfícticos y sexuales. Todos ellos pueden determinar uno o más de los supuestos comprendidos en los delitos de lesiones graves y gravísimas. El peligro de vida y las secuelas psicológicas son inherentes a la tortura. En las mujeres embarazadas, todo los métodos de tortura reseñados son eficaces para interrumpir el aborto o el adelantamiento del parto.

Palabras clave: Tortura

Violaciones de los derechos humanos

Medicina Legal

Uruguay

\section{Introducción}

La Medicina Legal tiene entre sus misiones el diagnóstico de la tortura como forma de contribución a las investigaciones judiciales y a la reparación de las víctimas $^{(1-5)}$.

Los contextos en los que se desarrolla la tortura son muy variables, al igual que los métodos empleados al efecto. Por ello, más allá de los principios de carácter general, se justifica un estudio ad hoc enfocado a las condiciones de tiempo y de lugar concretas ${ }^{(6,7)}$.

En Uruguay se desarrollan numerosos procedimientos administrativos y criminales referidos al período del terrorismo de Estado, definido por la Ley $\mathrm{N}^{\circ}$ 18.596, de 18 de setiembre de 2009, como "el quebrantamiento del Estado de Derecho que impidiera el ejercicio de derechos fundamentales a las personas, en violación a los Derechos Humanos o a las normas del Derecho Internacional Humanitario, en el periodo comprendido desde el 27 de junio de 1973 hasta el 28 de febrero de 1985" (artículo 1). Por la misma norma, el Estado uruguayo reconoció su responsabilidad en "la realización de prácticas sistemáticas de tortura, desaparición forzada y prisión sin intervención del Poder Judicial, homicidios, aniquilación de personas en su integridad psicofísica, exilio político o destierro de la vida social, en el periodo comprendido desde el 13 de junio de 1968 hasta el 26 de junio de 1973 (...)" (artículo 2). Asimismo, definió como "víctimas del terrorismo de Estado" a "todas aquellas personas que hayan sufrido la violación a su derecho a la vida, a su integridad psicofísica y a su libertad dentro y fuera del territorio nacional, desde el 27 de junio de 1973 hasta el 28 de febrero de 1985, por motivos políticos, ideológicos o gremiales. Dichas violaciones deberán haber

$\begin{array}{ll}\text { Key words: } & \text { Torture } \\ & \text { Human rights abuses } \\ & \text { Forensic Medicine } \\ & \text { Uruguay }\end{array}$

sido cometidas por parte de agentes del Estado o de quienes, sin serlo, hubiesen contado con la autorización, apoyo o aquiescencia de los mismos" (artículo 4).

El delito de tortura se tipificó en Uruguay en el artículo 22 de la Ley $\mathrm{N}^{\mathrm{o}} 18.026$, de 26 de setiembre de 2006, en la forma que sigue y en consonancia con la Convención contra la Tortura y Otros Tratos o Penas Crueles, Inhumanos o Degradantes de las Naciones Unidas (1984):

"22.1. El que de cualquier manera y por cualquier motivo, siendo agente del Estado o sin serlo contando con la autorización, apoyo o aquiescencia de uno o más agentes del Estado impusiere cualquier forma de tortura a una persona privada de libertad o bajo su custodia o control o a una persona que comparezca ante la autoridad en calidad de testigo, perito o similar, será castigado con veinte meses de prisión a ocho años de penitenciaría.

22.2. Se entenderá por 'tortura':

A) Todo acto por el cual se inflija dolores o sufrimientos graves, físicos, mentales o morales.

B) El sometimiento a penas o tratos crueles, inhumanos o degradantes.

C) Todo acto tendiente a anular la personalidad o disminuir la capacidad física o mental aunque no cause dolor ni angustia física o cualquier acto de los previstos en el artículo 291 del Código Penal realizado con fines indagatorios, de castigo o intimidación.

22.3. No se entenderá por tortura el dolor o los sufrimientos que se deriven únicamente de sanciones lícitas o que sean consecuencia normal o fortuita de ellas" (8).

Amén de su definición legal, la tortura requiere de un diagnóstico médico-legal, en base a la comprobación de una constelación de síntomas y signos físicos y psíqui- 
cos, más o menos específicos, en dependencia de los métodos empleados para infligir dolor y sufrimiento ${ }^{(6)}$.

Si bien la tortura es un delito de lesa humanidad imprescriptible, en la jurisprudencia nacional se ha desestimado su tipificación en aquellos casos ocurridos con anterioridad a la Ley $\mathrm{N}^{\circ} 18.026$, en base al principio de no retroactividad de la ley penal. En este contexto jurídico, el Departamento de Medicina Legal y Ciencias Forenses de la Facultad de Medicina de la Universidad de la República ha recibido numerosas solicitudes de informes de diferentes sedes judiciales, a iniciativa de la Fiscalía Especializada en Crímenes de Lesa Humanidad, respecto de la posibilidad de que los métodos de tortura aplicados en el período del terrorismo de Estado pudieran ocasionar a las víctimas lesiones graves o gravísimas, tal como las tipifica el Código Penal Uruguayo (en adelante: CPU).

Este trabajo recoge y sistematiza la experiencia desarrollada por el Departamento de Medicina Legal y Ciencias Forenses en la elaboración de estos informes judiciales.

\section{Objetivos}

Objetivo general: contribuir al conocimiento de los crímenes del terrorismo de Estado en Uruguay, aportando así a la realización de los estándares internacionales de verdad, justicia, memoria y reparación.

\section{Objetivos específicos}

1. Describir los métodos de tortura empleados por el terrorismo de Estado en Uruguay.

2. Determinar su idoneidad para producir lesiones graves o gravísimas en las víctimas.

\section{Metodología}

Se estudiaron los resultados de las investigaciones históricas nacionales sobre el terrorismo de Estado, así como la jurisprudencia firme en la materia, donde se establecen los métodos de tortura empleados.

Se revisó la bibliografía relevante sobre las lesiones y secuelas resultantes de la tortura en sus diferentes variantes.

La limitada casuística de práctica pericial en el examen de víctimas vivas o muertas de la tortura se palió con la aplicación de la analogía con situaciones asimilables y de los principios generales de la fisiopatología (por ejemplo: síndrome de casi ahogamiento con el submarino húmedo).

Para la interpretación médico-legal de los supuestos fácticos incluidos en los tipos penales de lesión grave y gravísima se aplicaron los consensos interdisciplinarios actuales publicados por el Departamento de Medicina Legal y Ciencias Forenses ${ }^{(9)}$.

\section{Resultados}

\section{Métodos de tortura física usados por el terrorismo de Estado en Uruguay}

La práctica de la tortura es conocida, al menos, desde la Antigüedad. Los métodos aplicados han sido cambiantes a lo largo de la historia, así como entre los diferentes países. En el territorio de la Banda Oriental se han descrito métodos autóctonos desde la época colonial ${ }^{(10)}$.

Todos los métodos de tortura física suponen un sufrimiento psicólogo, además de que habitualmente se acompañan de técnicas especialmente dirigidas al daño psíquico, como el aislamiento, la obligación de presenciar sesiones de tortura o el simulacro de fusilamien$\operatorname{tos}^{(6)}$.

En el período del terrorismo de Estado en Uruguay ha sido característica la aplicación de torturas a gran escala y en forma sistemática. La bibliografía, la experiencia pericial, la jurisprudencia y la investigación histórica permiten conocer los métodos de tortura más frecuentemente aplicados en Uruguay durante ese perío$\mathrm{do}^{(11-16)}$.

a) El encapuchamiento (consiste en colocar una bolsa de tela cubriendo la cabeza ajustada al cuello con una soga o bien una venda ajustada sobre los ojos de los prisioneros) también era una práctica sistemática, en general, desde el momento de la detención y durante todo el período de los interrogatorios, lo que se prolongaba por días, semanas o meses ${ }^{(6,11,15-20)}$.

b) Tanto la privación de agua, alimentos y reposo, como la exposición al frío, se usaron como forma de tortura por omisión de los cuidados y satisfacción de las necesidades básicas de los detenidos, capaces de debilitarlos física y psicológicamente. Para la privación del sueño, se emplearon estímulos auditivos y luminosos. La exposición al frío incluye obligar a permanecer desnudos a los detenidos (a veces a la intemperie), así como no permitirles el uso de ropa de cama y abrigo durante el sueño ${ }^{(12,16,17,20)}$.

c) Las golpizas pueden propinarse con diferentes instrumentos contundentes, como cachiporras, bastones o armas naturales, mediante golpes de puño o puntapiés. Las regiones elegidas incluyen regiones sensibles al dolor, como el epigastrio o los genitales externos. Algunas topografías (especialmente en todo el sector anterolateral del abdomen) pueden ser asiento de traumatismos de elevada energía mecánica sin producir signos objetivables al examen externo, aunque sí en la autopsia (la piel aparenta estar indemne, pero hay un infiltrado hemorrágico en el tejido celular, el plano muscular o las vísceras profundas) ${ }^{(6,11,12,16,1,20-23)}$. 
d) La tortura conocida como teléfono consiste en aplicar traumatismos repetidos sobre los pabellones auriculares. Se ha descrito tanto mediante golpes directos con las palmas del agresor como con la interposición de la capucha o previa colocación de un balde sobre la cabeza de la víctima ${ }^{(4,17)}$.

e) El método del plantón consiste en obligar al detenido a permanecer de pie durante lapsos prolongados. Se describen diferentes variantes, como los pies en separación forzada, los miembros superiores extendidos lateralmente, a veces sosteniendo pesos. Esta tortura generalmente se aplicaba a un detenido maniatado, encapuchado y bajo privación de sueño, hidratación y alimentación ${ }^{(12,17,18,20)}$.

f) El colgamiento o gancho consiste en la suspensión de la víctima en posiciones variadas. Entre ellas, era de uso extendido la suspensión por las muñecas, previamente atadas o esposadas a la espalda, mediante el uso de una cuerda o cadena y una roldana ("suspensión palestina"). La víctima también puede ser suspendida por la cintura, las rodillas, los tobillos o los pulgares. La suspensión puede ser completa o incompleta. En la variante incompleta la víctima es izada de tal modo de permitirle alcanzar a tocar el piso con el extremo distal de los pies. De esta manera, al sufrimiento de las estructuras articulares y periarticulares de los hombros y las muñecas se le añade el de los tobillos y los pies. El colgamiento puede combinarse con choques eléctricos, traumatismos con objetos contundentes y agresiones sexuales ${ }^{(6,12,16,17,24,25)}$.

g) El caballete o potro es otro de los métodos de tortura posicional (aquellos en los que las molestias, el dolor y el agotamiento viene de la adopción de una postura estática, forzada y antifisiológica), por el que se coloca a la víctima sentada a horcajadas sobre un filo o borde generando un daño pasivo por el propio peso. Generalmente, la víctima está encapuchada y tiene las muñecas y los tobillos inmovilizados. La bibliografía lo menciona como un método de tortura creado en Uruguay en las unidades militares del arma de Caballería ${ }^{(11,12)}$.

h) El submarino (waterboarding), con diferentes variantes, fue usado "legalmente" desde la Inquisición (siglo XIV) hasta 2009 (año en que se puso fin a la autorización expresa dada en 2003 por el Departamento de Estado de Estados Unidos para su aplicación a los prisioneros de la prisión de Guantánamo). Consiste en sumergir la cabeza de la víctima en un medio líquido, que generalmente es agua sucia o mezclada con orina y excremento (submarino húmedo o tacho), o cubriendo la cabeza con una bolsa plástica o la propia capucha. La inmersión de la ca- beza puede ser precedida de la aplicación de una contusión epigástrica intensa que fuerce una espiración forzada de la víctima, obligándola así a inspirar bajo agua ${ }^{(6,11,12,15-18,20,24-26)}$.

i) La picana eléctrica, método de tortura cuyo origen algunos autores ubican en Argentina, consiste en la aplicación de choques eléctricos en diferentes regiones corporales, especialmente en las de mayor sensibilidad, como labios, dientes, oídos, aréolas o genitales. Puede ser aplicada mediante la picana propiamente dicha (un electrodo metálico que contacta sobre la piel o las mucosas) o el magneto o teléfono (un sistema a manivela que genera corriente continua que es transmitida a través de cables conductores que se fijan al cuerpo). Puede aplicarse con la víctima inmovilizada sobre una parrilla metálica o suspendida del gancho. En ocasiones se aplica combinada con el uso de agua para magnificar sus efectos ${ }^{(5,6,11,12,18}$, 23-25,27)

j) Las agresiones sexuales se aplicaron tanto en mujeres como en hombres. Incluyen desde la obligación de permanecer desnudo frente a los interrogadores como los tocamientos, la introducción de cuerpos extraños en la vagina o el recto y la violación ${ }^{(6,11,12,17,24)}$.

\section{Idoneidad de los métodos de torturas empleados para provocar lesiones graves o gravísimas}

El CPU define una lesión personal como "cualquier trastorno fisiológico del cual se derive una enfermedad del cuerpo o de la mente" provocado a un tercero sin intención de matar (artículo 316, CPU).

A su vez, tipifica las lesiones graves y gravísimas, que son el motivo de este estudio, como sigue:

"Artículo 317 (Lesiones graves)

La lesión personal (...) es grave (...) si del hecho se deriva:

1. Una enfermedad que ponga en peligro la vida de la persona ofendida, o una incapacidad para atender las ocupaciones ordinarias, por un término superior a veinte días.

2. La debilitación permanente de un sentido o de un órgano.

3. La anticipación del parto de la mujer ofendida. Artículo 318 (Lesiones gravísimas)

La lesión personal es gravisima (...) si del hecho se deriva:

1. Una enfermedad cierta o probablemente incurable.

2. La pérdida de un sentido.

3. La pérdida de un miembro o una mutilación que le torne inservible o la pérdida de un órgano, o de la capa- 
cidad de generar, o una grave y permanente dificultad de la palabra.

4. Una deformación permanente del rostro.

5. El aborto de la mujer ofendida".

\section{Consideraciones generales sobre los efectos de la tortura}

Definida la tortura, los métodos de tortura aplicados en Uruguay por el terrorismo de Estado y los tipos penales, queda fuera de toda controversia que la aplicación intencional de dolor o sufrimientos graves físicos o mentales sobre una persona constituye un medio eficaz para el menoscabo de su integridad física y psicológica. La tortura siempre ocasiona un daño agudo, generalmente determina secuelas y, en ocasiones, causa la muerte de la víctima ${ }^{(4,6,21,22)}$.

Cuando la consecuencia de la tortura es una secuela (daño consolidado) supone, cuando menos, el debilitamiento de un miembro, un órgano o una función (artículo 317, CPU), aunque también puede llegar a la pérdida de un miembro, un órgano, una función o un sentido (artículo 318, CPU) $)^{(9)}$.

Por otra parte, cuando de la tortura se deriva una enfermedad (proceso activo) que se prolonga en el tiempo (crónico), con su cortejo de signos y síntomas, y es refractaria a los tratamientos curativos, estaremos frente a una enfermedad (física o psíquica) cierta o probablemente incurable (artículo 318, CPU) ${ }^{(9)}$. Dentro de estas evoluciones a la cronicidad, cabe citar como ejemplo, por su frecuencia, el dolor crónico (a veces explicado por un daño físico localizado y en otras como respuesta psíquica al trauma padecido) y las patologías ósteo-articulares $^{(6,12,21,24,27-29)}$.

En relación con la esfera psíquica, cualquiera sea el método de tortura utilizado, puede generar alteraciones mentales. En particular, hay que subrayar que la tortura es una de las etiologías típicas del trastorno por estrés postraumático crónico, afección psiquiátrica de evolución tórpida y recurrente, cuyos tratamientos solo logran, en los casos más favorables, aliviar parcialmente la sintomatología que aflige a los pacientes. La exposición repetida a situaciones traumatizantes determina un daño psíquico acumulativo que puede dar lugar a la entidad conocida como trauma complejo. Otras enfermedades psiquiátricas que se pueden asociar con haber padecido la tortura son la depresión, los trastornos por ansiedad, los trastornos del sueño, las disfunciones sexuales psicógenas y las adicciones, entre otras ${ }^{(6,12,24,27,29-33)}$.

Respecto a la posibilidad de poner en peligro la vida de la víctima (artículo 317, CPU), toda tortura física supone, en principio, la eventualidad de un desenlace letal. Es habitual en los centros de tortura la presencia de médicos que controlan las funciones vitales de los dete- nidos. En algunos casos, la propia naturaleza del método acarrea riesgos vitales específicos muy evidentes (por ejemplo, la asfixia en el submarino), mientras que otros ponen en marcha mecanismos fisiopatológicos inespecíficos (por ejemplo, el paro cardiorrespiratorio como respuesta refleja al dolor agudo o al estrés psicofísico). De hecho, toda pérdida de conocimiento (como las que pueden ocurrir durante las sesiones de tortura) califica como "peligro de vida", según la práctica médico forense cotidiana ${ }^{(9,11,21)}$.

La bibliografía destaca que la muerte puede ocurrir tanto durante el acto de la tortura como en forma diferida. Durante la tortura la muerte puede sobrevenir bruscamente, especialmente (pero no exclusivamente) en víctimas portadoras de patologías cardiovasculares favorecedoras, que en ocasiones son subclínicas. Las muertes diferidas reconocen muy diversos mecanismos, como la falla cardíaca, circulatoria, neurológica, respiratoria o renal. También se reconocen como muerte causada por la tortura aquellas relacionadas con las condiciones de reclusión (privación de alimentos, agua o asistencia médica) y algunas no directamente vinculadas a las lesiones producidas en la tortura (suicidio en la celda tras las sesiones de tortura) ${ }^{(1,20-23)}$.

En el caso de las mujeres en estado de gravidez resulta palmario que todo método de tortura es capaz de adelantar el parto o de ocasionar el aborto, según la viabilidad del producto. El intenso estrés psicofísico a que están sometidas las mujeres víctimas de la tortura es un estímulo eficaz para desencadenar contracciones uterinas que ponen fin al proceso de la gestación, expulsando al producto, con o sin chance de sobrevida extrauterina.

Para valorar la eficacia de cada modalidad de tortura para producir lesiones graves o gravísimas se debe tomar en cuenta que generalmente se emplean varios métodos, sucesivos o simultáneos, que incluyen agresiones físicas, psicológicas o sexuales, así como que transcurre en contextos singularmente estresantes y operando sobre un terreno habitualmente muy desfavorable, fruto de un proceso de desgaste psicofísico que suele incluir limitaciones en el descanso, la alimentación y la asistencia médica oportuna ${ }^{(6,11,16,18,20-22,24)}$.

\section{Efectos de la privación de agua, alimentos, descanso y de la exposición al frío}

Estas modalidades de tortura por omisión determinan una particular vulnerabilidad de las víctimas que favorece la adquisición de enfermedades infecciosas, alteraciones del medio interno, alteraciones psíquicas o descompensación de patologías preexistentes capaces de poner en peligro la vida (por ejemplo, neumonías, delirio, deshidratación, diselectrolitemias, hipoglicemia). 
Siempre en relación con la intensidad y duración de la agresión, pueden determinar incapacidades mayores a veinte días por patologías diversas, como la desnutrición o el estrés postraumático agudo, entre otras.

En la mujer embarazada todas estas modalidades de tortura pueden determinar tanto el aborto como el adelantamiento del parto.

\section{Efectos de las golpizas}

Las golpizas pueden generar un enorme abanico de lesiones y secuelas, según sea la intensidad y la topografía elegida para la agresión traumática ${ }^{(6,34)}$.

La muerte por golpizas (beaten to death en la bibliografía anglosajona) puede obedecer a diversas causas, la mayoría de ellas detectables en la autopsia y en los estudios histopatológicos. Es el caso de los sangrados internos por rotura de vísceras macizas, como el hígado, el bazo o los riñones, que generan anemia aguda, seguida de shock hipovolémico y muerte. También pueden llevar al estallido de vísceras huecas, así como isquemia, necrosis y perforación intestinal seguida de peritonitis ${ }^{(21,34)}$.

En el tórax, las contusiones de pulmón, corazón y grandes vasos pueden evolucionar a la muerte. Las lesiones intracraneanas, como las hemorragias meníngeas (subdurales cuando hay integridad del cráneo o extradurales cuando hay fractura de la calota) o las contusiones cerebrales pueden ser mortales, generalmente por aumento de la presión intracraneana ${ }^{(6)}$.

Las golpizas en los miembros o en la región lumbar pueden generar desprendimientos de émbolos grasos que ocasionen la oclusión parcial o total de algún vaso y consecuentemente la muerte (por ejemplo, embolia grasa pulmonar). También pueden llevar al desarrollo de rabdomiolisis con alteraciones del medio interno que predisponen a arritmias cardíacas, falla respiratoria y falla renal aguda ${ }^{(5,6,34)}$.

En caso de traumatismo abdómino-pélvico en la mujer embarazada, pueden producirse complicaciones potencialmente mortales que dependerán de la edad gestacional. En cualquier caso, las consecuencias deletéreas pueden ser tanto maternas como fetales. En la primera mitad del embarazo puede producirse el aborto y retención de restos que podrían conducir a infección y sepsis. En la segunda mitad pueden producirse complicaciones potencialmente mortales, como el desprendimiento de placenta o la rotura uterina seguida de shock hemorrágico, lo que además del riesgo letal determina hipoperfusión placentaria con anoxia fetal.

Sumado a lo antedicho se han descrito casos de sufrimiento y muerte fetal postraumática luego de un traumatismo materno leve por hipoperfusión placenta- ria, hematoma retroplacentario o hemorragia feto-placentaria $^{(35)}$.

Las contusiones reiteradas pueden causar la muerte (inmediata o diferida) por anemia aguda incluso sin lesión visceral, por secuestro sanguíneo en las partes blandas (piel, tejido celular y masas musculares) ${ }^{(5,21,22)}$.

En algunos casos la muerte obedece a un mecanismo funcional o inhibitorio de tipo reflejo frente al dolor, tras el estímulo en ciertas topografías especialmente sensibles, como el cuello, el epigastrio o los testículos. En esos casos la autopsia puede ser muy poco expresiva o completamente en blanco ${ }^{(5,21,34)}$.

El lapso de incapacidad provocado por las golpizas estará determinado por el tiempo y los sitios de aplicación de estas violencias traumáticas, dependiendo en última instancia de la naturaleza y gravedad de las lesiones causadas, incluyendo la repercusión psicológica en la víctima. Es frecuente que la afectación del sistema músculo-esquelético, como en el caso de luxaciones y fracturas, determinen inhabilitaciones superiores a los veinte días.

Las golpizas pueden generar secuelas diversas. Particularmente, los castigos en la cabeza pueden generar un variado espectro de lesiones y secuelas que debiliten o aun supongan la pérdida completa de una función. Es el caso de la lesión axonal difusa por el traumatismo directo o inercial de la cabeza, o las típicas lesiones oculares (dislocación del cristalino o desprendimiento de retina) que disminuyen el campo o la agudeza visual, o causan la pérdida de la visión en el ojo afectado. También los traumatismos en las orejas pueden comprometer severamente el sentido de la audición o, incluso, determinar su pérdida. Los castigos en la nariz y en la boca pueden generar lesiones en el tabique, luxaciones y pérdidas dentarias, respectivamente ${ }^{(6)}$.

Las contusiones en la cabeza pueden ser causa de la epilesia postraumática que evolucione a la cronicidad, dando lugar a una enfermedad cierta o probablemente incurable ${ }^{(36)}$.

Las fracturas de los miembros ocasionadas por la tortura, eventualmente agravadas por una inoportuna $o$ inadecuada asistencia, pueden evolucionar hacia limitaciones funcionales (por ejemplo, fractura de cadera seguida de acortamiento del miembro y cojera secuelar, consolidación viciosa con desviación del eje del miembro y limitaciones a la movilidad articular, o lesiones de nervios con la consiguiente secuela sensitivo o motora del territorio inervado).

Los castigos corporales con objetos contusos o armas naturales son eficaces para interrumpir el proceso de gestación, sea por el adelantamiento del parto con un recién nacido viable (con un grado de prematurez variable, dependiendo de la edad gestacional) o por un aborto 
(entendido desde el punto de vista médico-legal como el fin del embarazo con muerte del producto). De hecho, los traumatismos abdominales son un método conocido y cruento para la interrupción del embarazo.

Fuera de las hipótesis comunes a toda la práctica de la tortura, particularmente en la esfera psíquica (incluidos los de causa orgánica por traumatismos en la cabeza), cabría mencionar la posibilidad de las artrosis postraumáticas como una de las eventuales enfermedades incurables derivadas de las golpizas.

\section{Efectos del teléfono}

Esta variante de golpiza selectiva determina efectos muy específicos.

La posibilidad de un resultado letal depende de una muerte por inhibición a punto de partida de los estímulos dolorosos en el oído.

Si bien no necesariamente el haber padecido el teléfono determinará una incapacidad para las tareas ordinarias mayor a los veinte días (las lesiones timpánicas pequeñas pueden curar en diez días), esto es una posibili$\mathrm{dad}^{(6)}$. El lapso necesario para retomar las ocupaciones ordinarias estará determinado por la gravedad de los traumatismos y su repercusión funcional. Su estimación requerirá valorar cada caso concreto.

Este método de tortura se asocia típicamente con la afectación del sentido de la audición y de la función del equilibrio ejecutada por el oído interno. En los casos más favorables el daño puede ser reversible, en el caso de aquellas lesiones timpánicas que evolucionan al retitutio ad integrum (se recupera la anatomía y la función sin persistencia de secuelas). Igualmente son bien conocidas las lesiones traumáticas del oído que dejan secuelas sensoriales (disminución de la agudeza auditiva) y del equilibro (vértigos) $)^{(5,37)}$.

Como todo método de tortura, el teléfono puede provocar tanto el parto como el aborto de una víctima grávida.

Si bien la afectación de las funciones del oído ya referidas puede considerarse una secuela, una alteración crónica de la función del equilibrio refractaria al tratamiento, como la pueden provocar estos traumatismos, podría encuadrar en la categoría de enfermedad cierta o probablemente incurable tipificada en el artículo $318 \mathrm{del}$ CPU.

Además de lo anterior, las víctimas del teléfono pueden desarrollar las patologías psiquiátricas comunes a todo método de tortura.

\section{Efectos del plantón}

Como se señaló, esta tortura generalmente se aplicaba a un detenido generalmente maniatado, encapuchado y bajo privación de sueño, hidratación y alimentación, además de acompañarse de otras agresiones físicas y psicológicas. El grado del riesgo de vida dependerá del lapso por el que se prolongue el plantón, de su combinación con otros métodos de tortura, del terreno y el estado anterior de la víctima. El agotamiento psicofísico causado por el plantón, unido a la falta de agua, alimentación y sueño, es potencialmente letal.

El lapso de incapacidad es sumamente variable. Si bien no necesariamente el haber padecido el plantón determina una incapacidad para las tareas ordinarias mayor a los veinte días, esto es una eventualidad. El lapso real estará determinado, además de por factores constitucionales físicos y psíquicos individuales, por la duración de esa tortura y por otros tormentos asociados. La estimación del tiempo de inhabilitación requerirá siempre una valoración ad hoc.

No se asocia específicamente con la debilitación permanente de un órgano o un sentido. No obstante, además de la afectación psicológica, debe mencionarse el riesgo en personas susceptibles de desarrollar insuficiencia venosa de los miembros inferiores causada por la prolongada permanencia de pie sin desplazarse. Los daños en los tobillos y los pies (como edemas y dolores locales) generalmente resultan reversibles.

El plantón prolongado es eficaz para provocar tanto el aborto como la anticipación del parto, dependiendo de si la edad gestacional permite o no la viabilidad del producto.

Fuera de lo ya señalado, no se asocia con la aparición de enfermedades incurables específicas.

\section{Efectos del colgamiento o "gancho"}

Desde el punto de vista del riesgo vital, le caben las consideraciones generales comunes a todos los métodos de tortura. Además, en personas con patología respiratoria moderada a severa podría sobrevenir la muerte por asfixia posicional (variante de las sofocaciones a vía área libre) y la inmovilización prolongada de los miembros puede provocar alteraciones de la circulación, con formación y desprendimiento de trombos causantes de muerte súbita por tromboembolismo pulmonar. También pueden sobrevenir complicaciones isquémicas, necróticas o gangrenosas potencialmente letales.

El colgamiento durante períodos prolongados determina sufrimientos articulares, particularmente del hombro, con posible periartritis y, típicamente, luxación escápulo-humeral. Es bien conocida la lesión del plexo braquial, con afectación uni o bilateral de la inervación motora y sensitiva de los miembros superiores ${ }^{(9)}$.

Este método de tortura también puede producir lesiones isquémicas, y aun necrosis, de las manos causadas por las esposas o la cuerda que aferra las muñecas y sirven como punto de tracción. También está descrita la 
trombosis de las arterias radial y cubital por el colgamiento $^{(5)}$.

Todos estos daños secundarios al colgamiento, unido al sufrimiento psicológico, pueden determinar incapacidades por lapsos superiores a veinte días.

Los daños descritos pueden generar un daño permanente que debilite la función del hombro o de la mano. Así, por ejemplo, la luxación de hombro (uni o bilateral) puede ser del tipo recidivante o inveterada, limitando la funcionalidad de esa articulación y de todo el miembro superior. Aún más grave es la afectación neurológica del plexo braquial, que puede llevar a la plejia o la paresia del miembro afectado, acompañado por déficits sensitivos. En los casos en que se afecta gravemente la irrigación de las manos también pueden quedar secuelas anatómicas o funcionales ${ }^{(6,24)}$.

Los colgamientos, así como todas las torturas que se basan en la adopción forzada y permanente de posturas corporales anormales (las llamadas stress positions en la literatura anglosajona) pueden provocar tanto la anticipación del parto como el aborto.

Adicionalmente a las hipótesis comunes a toda la práctica de la tortura, particularmente las correspondientes a la esfera psíquica, las víctimas del "gancho" son más proclives al desarrollo de secuelas ósteo-articulares que de enfermedades activas incurables con nexo causal con esa tortura.

\section{Efectos del caballete o "potro"}

Es otro de los métodos de tortura posicionales y no presenta un mecanismo potencialmente letal específico, sino que conlleva el peligro de vida inherente a la práctica de la tortura con sus distintos métodos, a punto de partida del estrés psicofísico que determina.

El lapso de incapacidad determinado por el padecimiento del caballete es variable y estará determinado por su prolongación en el tiempo, la producción de lesiones en la región perineal y el daño psíquico provocado.

Si bien no se asocia característicamente con la debilitación permanente de un órgano o un sentido específicos, el trauma perineal puede ocasionar lesiones a nivel de las partes blandas y de las estructuras neurovasculares (particularmente los nervios pudendos), con posible afectación de las funciones urinaria y sexual. El compromiso de la función sexual por afectación de la inervación o la irrigación podría determinar la pérdida funcional copulatoria del pene y con ella "la capacidad de generar", según la clásica categoría médico-legal de impotencia coeundi, o la actual disfunción eréctil ${ }^{(38,39)}$.

La tortura por el método del caballete en una mujer embarazada puede provocar tanto la anticipación del parto como el aborto.
Las consecuencias de este método de tortura pueden ser causa de procesos morbosos activos crónicos y sin tratamiento curativo en las esferas psíquica, urinaria y sexual, calificando así como "enfermedad cierta o probablemente incurable” (artículo 318 del CPU).

\section{Efectos del submarino}

Tanto el submarino seco (modalidad de la sofocación facial) como el submarino húmedo (modalidad de sumersión incompleta) determinan un riesgo vital ${ }^{(5)}$.

En el caso del submarino seco, se trata de una asfixia por sofocación facial, por oclusión de los orificios respiratorios (fosas nasales y boca), lo que determina una asfixia pura por privación de oxígeno. La muerte se produce por la prolongación de este impedimento al ingreso de oxígeno al árbol respiratorio, aunque también puede producirse una muerte súbita por un mecanismo inhibitorio debido a la manipulación brusca por parte de quienes llevan adelante la tortura de algunas de las estructuras reflexógenas situadas en el cuello durante la acción de vencer la resistencia de la víctima a sumergir la cabeza $^{(34,40)}$.

En el caso del submarino húmedo, además del mecanismo asfíctico propiamente dicho, se ponen en juego alteraciones electrolíticas en la sangre generadas en la interface alvéolo-capilar que pueden causar arritmias cardíacas y la muerte.

Cuando la sumersión es en un medio líquido contaminado (como la materia fecal), se añaden los riesgos de neumonía, sinusitis, meningitis y sepsis, que pueden llevar a la muerte en forma diferida ${ }^{(5,6,24)}$.

El lapso de incapacidad determinado por el submarino es incierto, dependiendo de su duración, del número de sesiones y del daño sufrido (pulmonar, de otros parénquimas y psicológico).

El submarino puede producir la debilitación permanente de un órgano o un sentido en las víctimas. El principal daño a considerar en el submarino es la lesión pulmonar provocada por el esfuerzo inspiratorio con la vía aérea inundada por el medio líquido de la sumersión, lo que genera rotura alveolar y focos de hemorragia, causantes de enfisema y pueden evolucionar a la fibrosis pulmonar. Esto determina una limitación de la función respiratoria, que será proporcional al daño anatómico y puede ser cuantificable mediante el estudio funcional respiratorio.

En términos generales, la privación prolongada de suministro de oxígeno tisular podría llegar a provocar la falta de irrigación de algunos parénquimas nobles sensibles a la hipoxia, como el encéfalo, el miocardio o los riñones, con un daño reversible o irreversible a ese nivel.

$\mathrm{Al}$ igual que los otros métodos de tortura, la aplicación del submarino en cualquiera de sus formas a una 
mujer embarazada puede provocar la interrupción del embarazo, anticipando el parto o produciendo el aborto.

Las mencionadas consecuencias sobre la función respiratoria aplican más como secuelas que limitan la función que como enfermedades incurables, lo que requeriría cumplir con el criterio de ser un proceso activo (en cuyo caso sí sería una enfermedad cierta o probablemente incurable) (artículo 318, CPU).

Desde luego, las víctimas del submarino pueden llegar a desarrollar patologías psiquiátricas incurables, particularmente el trastorno por estrés postraumático ${ }^{(33)}$.

\section{Efectos de la picana eléctrica}

La tortura mediante choques eléctricos es potencialmente letal, por mecanismos específicos o inespecíficos, que pueden asociarse tanto a convulsiones como a síncope o fibrilación ventricular ${ }^{(5,24)}$.

Toda muerte por electrocución es de difícil diagnóstico autópsico, salvo cuando existen grandes lesiones de entrada y salida, lo que ocurre con corrientes y voltajes mucho mayores a los usados en la tortura eléctrica. Resulta fundamental el estudio del lugar del hecho (raramente disponible en el caso de la tortura) y la identificación de pequeñas lesiones en piel o mucosas (a veces imperceptibles) producidas por la picana o los cables. Suele causar lesiones de piel reversibles, aunque a veces son evidentes macroscópicamente. Se acepta que la identificación de estas lesiones en un cadáver, en ausencia de otra causa de muerte evidente, permite establecer el diagnóstico ${ }^{(5,6,21)}$.

El tiempo de inhabilitación dependerá de la duración, intensidad y número de sesiones padecidas, así como del tipo de daño producido. La incapacidad puede deberse a rigidez de los miembros, por compromiso reversible de sectores del sistema nervioso periférico, además del estrés postraumático agudo.

Es usual que se produzca un debilitamiento de las regiones afectadas, especialmente por lesión neurológica que, en general, revierte en días o semanas. En los casos de lesiones eléctricas de mayor gravedad podría llegar a causarse un daño permanente con limitación funcional secundaria a luxaciones y radiculopatías. Está descrita la impotencia como una posible secuela ${ }^{(6,24)}$.

Naturalmente la tortura mediante choques eléctricos siempre puede anticipar el parto o causar el aborto en una víctima grávida. Esto es particularmente evidente, aunque no exclusivo, en los casos en que los sitios de las descargas eléctricas son la vulva, la vagina o el cuello uterino.

La tortura eléctrica puede ser causa de una enfermedad psíquica cierta o probablemente incurable, es decir, sin tratamiento curativo conocido. El ejemplo más típico es el trastorno por estrés postraumático ${ }^{(33)}$.

\section{Efectos de las agresiones sexuales}

Los efectos de la tortura sexual dependerán de la modalidad de agresión empleada. En los casos de penetración vaginal o anal, o mediante el uso de cuerpos extraños, existe el riesgo de muerte súbita por inhibición. En casos de empalamiento, puede provocar lesiones penetrantes abdómino-pélvicas potencialmente mortales por complicaciones hemorrágicas o infección.

El lapso de inhabilitación es sumamente variable, dependiendo de los daños físicos y psicológicos causados.

Según la región afectada, pueden producirse lesiones traumáticas y hemorrágicas genitales o anorrectales, que pueden curar o determinar secuelas funcionales de gravedad variable, particularmente de la esfera psíquica, sexual o de la defecación ${ }^{(6,21)}$.

También existe la eventualidad del contagio venéreo o el embarazo con los eventuales daños psicológicos derivados ${ }^{(6)}$.

El trastorno por estrés postraumático, la depresión crónica y los trastornos de la sexualidad son consecuencias frecuentes de la tortura sexual. Tanto para los trastornos antedichos, así como para el contagio de ciertas infecciones de transmisión sexual crónicas (por ejemplo, el virus de inmunodeficiencia humana), aplican como "enfermedad cierta o probablemente incurable" prevista en la ley penal.

En el caso de mujeres embarazadas las agresiones sexuales pueden llevar a la interrupción de la gestación con muerte del producto o el adelantamiento del parto.

\section{Conclusiones}

La revisión de la bibliografía y la jurisprudencia muestra la existencia de un patrón en la metodología de la tortura sistemática empleada durante el terrorismo de Estado en Uruguay que incluye métodos omisivos (exposición al frío, privación de agua, alimentos y descanso), posicionales (plantón, caballete, colgamiento), traumáticos (golpizas y teléfono), eléctricos, asfícticos (submarino seco y húmedo) y sexuales.

Todos estos métodos de tortura física resultan idóneos para ocasionar lesiones y secuelas que encuadran en diversos supuestos de los delitos de lesiones graves y gravísimas previstas en la ley penal uruguaya. Además del peligro de vida y las secuelas psicológicas inherentes a la tortura, los distintos métodos determinan incapacidades o enfermedades activas incurables específicas, según sea su mecanismo fisiopatológico de injuria física y psíquica. En las mujeres embarazadas todos los métodos de la tortura reseñados son eficaces para provocar el aborto o el adelantamiento del parto. 


\section{Bibliografía}

1. Stan CA. Forensic standardizations in torture and death in custody investigations. Interv Med App Sci 2012; 4(4):210-6.

2. Thomsen JL, Helweg-Larsen K, Rasmussen OV. Amnesty International and the forensic sciences. Am J Forensic Med Pathol 1984; 5(4):305-11.

3. Thomsen JL, Voigt J. Forensic medicine and human rights. Forensic Sci Int 1988; 36(1-2):147-51.

4. Thomsen JL. The role of the pathologist in human rights abuses. J Clin Pathol 2000; 53(8):569-72.

5. Saukko P, Knight B. Abuse of Human Rights: deaths in custody. En: Saukko P, Knight B, eds. Knight's Forensic Pathology. $4^{\text {th }}$ ed. Florida: CRC, 2016:299-310.

6. ONU. Oficina del Alto Comisionado de Derechos Humanos. Manual para la investigación y documentación eficaces de la tortura y otros tratos o penas crueles, inhumanos o degradantes (Protocolo de Estambul). Ginebra: ONU, 2004.

7. Rodríguez Almada H. Legal Medicine and Forensic Science in Uruguay. En: Ubelaker DH, ed. The Global Practice of Forensic Science. Oxford: Wiley, 2015:335-49.

8. Naciones Unidas. Derechos Humanos. Oficina del Alto Comisionado. Convención contra la tortura y otros tratos o penas crueles, inhumanos o degradantes. Ginebra, 1984. Disponible en: www.ohchr.org/SP/ProfessionalInterest/Pages/CAT.aspx [Consulta: 14 set. 2018].

9. Rodríguez Almada H, Olivera Negrín J, Alves A, Mederos D. Delitos contra la personalidad física: traumatismo, lesiones y violencia doméstica. En: Rodríguez Almada H, coord. Medicina Legal. Derecho Médico. Montevideo: Oficina del Libro-FEFMUR, 2017:209-24.

10. Mederos D. Enchalecamiento: un método de suplicio y ajusticiamiento de la época colonial. Reseña histórica y consideraciones médico-legales. Rev Méd Urug 2007; 23:203-6.

11. Rico A, coord. Investigación histórica sobre dictadura y terrorismo de estado en Uruguay (1973-1985). Montevideo: UdelaR, 2008.

12. Yarzábal L. La tortura como enfermedad endémica en América Latina: sus características en Uruguay. Nueva antropol 1985; 7 (28):75-92.

13. Uruguay. Presidencia de la República. Informe final de la Comisión para la Paz. Uruguay, 2003. Disponible en: www.archivo.presidencia.gub.uy/noticias/archivo/2003/abril/Informe_final.doc [Consulta: 14 set. 2018].

14. Rico A, coord., Barrán JC, Caetano G. Investigación histórica sobre detenidos desaparecidos. Montevideo: IMPO, 2007.

15. Observatorio Luz Ibarburu. Base de Jurisprudencia. Juzgado Letrado en lo Penal de $10^{\circ}$ turno. Sentencia $n^{\circ} 34 / 2013$. Montevideo, 29 de abril de 2013. Disponible en: https://www. observatorioluzibarburu.org/media/uploads/sent_2904-13_homicidio_dalmao_jueza_sanchez.pdf [Consulta: 17 set. 2018].

16. Observatorio Luz Ibarburu. Base de Jurisprudencia. Sentencia $\mathrm{n}^{\mathrm{o}} 36$. Montevideo, 26 de marzo de 2009. Juzgado Le- trado en lo Penal de $19^{\circ}$ turno. Disponible en: https://www. observatorioluzibarburu.org/media/uploads/98_247_2006.pdf [Consulta: 17 set. 2018].

17. Chile. Informe de la Comisión Nacional sobre prisión política y tortura. Chile, 2004. Disponible en: http://www.derechoshumanos.net/paises/America/derechos-humanos-Chile/informes-comisiones/Informe-Comision-Valech.pdf [Consulta: 17 set. 2018].

18. Observatorio Luz Ibarburu. Base de Jurisprudencia. Montevideo, 6 de Febrero de 2013. Juzgado Letrado en lo Penal de $7^{\circ}$ turno. Disponible en: http://www.observatorioluzibarburu.org/media/uploads/88972010.pdf [Consulta: 17 set. 2018].

19. Uruguay. Poder Judicial. Base de Jurisprudencia Nacional Pública. Tribunal de Apelaciones $2^{\circ}$ turno. Sentencia $n^{\circ}$ 204/2010. Montevideo, 26 de junio de 2010. Disponible en: http://bjn.poderjudicial.gub.uy/BJNPUBLICA/hojaInsumo2.seam?cid=8354 [Consulta: 17 set. 2018].

20. Observatorio Luz Ibarburu. Base de Jurisprudencia. Juzgado Letrado en lo Penal de $7^{\circ}$ turno. Auto de procesamiento. Montevideo, 2 de setiembre de 2015. Disponible en: https://www.observatorioluzibarburu.org/media/uploads/Perrini_auto_procesamiento_2setiembre2015.pdf [Consulta: 17 set. 2018].

21. Pollanen MS. The pathology of torture. Forensic Sci Int 2018; 284:85-96.

22. Uruguay. Poder Judicial. Base de Jurisprudencia Nacional Pública. Tribunal de Apelaciones $4^{\circ}$ turno. Sentencia $n^{\circ}$ 405/2012, Montevideo, 15 de noviembre de 2012. Disponible en: http://bjn.poderjudicial.gub.uy/BJNPUBLICA/hojaInsumo2.seam?cid=7757 [Consulta: 17 set. 2018].

23. Observatorio Luz Ibarburu. Base de Jurisprudencia. Juzgado Letrado en lo Penal de $4^{\circ}$ turno. Sentencia n ${ }^{\circ}$ 1825/2011. Montevideo, 31 de octubre de 2011. Disponible en: https://www.observatorioluzibarburu.org/causas/39 [Consulta: 17 set. 2018].

24. Saenz M, Liñán Fuentes L, Camargo Y. Tortura. En: Téllez Rodríguez N, coord. Patología forense: un enfoque centrado en derechos humanos. t. 2 Bogotá: Universidad de Colombia, 2014:535-243.

25. Observatorio Luz Ibarburu. Base de Jurisprudencia. Sentencia $\mathrm{n}^{\mathrm{o}}$ 157/2009. Montevideo, 21 de Octubre de 2009. Juzgado Letrado en lo Penal de $19^{\circ}$ turno. Disponible en: http://www.observatorioluzibarburu.org/media/uploads/3.\% 20Alvarez_y_Larcebeau $\% 20$ sent $\% 20157 \% 20 \%$ 2021.10.2009.pdf [Consulta: 17 set. 2018].

26. Uruguay. Poder Judicial. Base de Jurisprudencia Nacional Pública. Tribunal de Apelaciones $3^{\mathrm{er}}$ turno. Sentencia $\mathrm{n}^{\mathrm{o}}$ 346/2011. Montevideo, 15 de noviembre de 2011. Disponible en: http://bjn.poderjudicial.gub.uy/BJNPUBLICA/hojaInsumo2.seam?cid=8306 [Consulta: 17 set. 2018].

27. Moisander PA. Edston E. Torture and its sequel -a comparison between victims from six countries. Forensic Sci Int 2003; 137(2-3):133-40. 
28. Williams AC, Peña CR, Rice AS. Persistent pain in survivors of torture: a cohort study. J Pain Symptom Manage 2010; 40(5):715-22.

29. Perera P. Physical methods of torture and their sequelae: a Sri Lankan perspective. J Forensic and Leg Med 2007; 14(3):146-50.

30. Madariaga C. Trauma psicosocial, trastorno de estrés postraumático y tortura. Santiago de Chile: Cintras, 2002.

31. Nickerson A, Garber B, Ahmed O, Asnaani A, Cheung J, Hofmann S, et al. Emotional suppression in torture survivors: relationship to posttraumatic stress symptoms and trauma-related negative affect. Psychiatry Res 2016; 242:233-9.

32. Weisleder $\mathbf{P}$, Rublee $\mathbf{C}$. The neuropsychological consequences of armed conflicts and torture. Curr Neurol Neurosci Rep 2018; 18(3): 9.

33. Miller L. PTSD and forensic psychology. Applications to civil and criminal law. Florida: Springer, 2015.

34. DiMaio VJ, DiMaio DJ. Forensic pathology. $2^{\text {th }}$ ed. Boca Raton, FL: CRC, 2001.

35. Tejerizo-García A, Teijelo AI, Nava E, Sánchez-Sánchez MM, García-Robles RM, Leiva A, et al. Traumatismo no penetrante en la gestante. Un caso de encefalopatía hipoxicoisquémica fetal después de accidente automovilístico materno. Clin Invest Ginecol Obstet 2002; 29:13-30.

36. Piccenna L, Shears G, O'Brien TJ. Management of post ] traumatic epilepsy: an evidence review over the last 5 years and future directions. Epilepsia Open 2017; 2(2):123-44.

37. Vargas Sanabria M. Valoración médico legal de la hipoacusia. Med leg Costa Rica 2012; 29(1):61-78.

38. Sánchez Ramos A, Godino Duran JA, Antonio Oliviero A. Disfunción eréctil de origen neurológico. Arch Esp Urol 2010; 63(8): 603-9.

39. Iranzo A. Estudio del concepto y valoración médico-legal de la impotencia genital. Anales Universidad de Valencia 1969; XXXIII. (Curso 1959-60-Cuaderno II).

40. Castelló A, Francés F, Rodríguez Almada H, Verdú $\mathbf{P}$. Estudio médico legal de las asfixias mecánicas. Comares, Granada: 2011: 144 p. 